\title{
Gim Proses Donor Darah Sebagai Alat Promosi Donor Darah
}

\section{Blood Donation Process Game as a Instrument for Blood Donor Promotion}

\author{
Galang Prihadi Mahardhika \\ Program Studi Teknik Informatika - Program Sarjana, Fakultas Teknologi Industri, \\ Universitas Islam Indonesia, Jl. Kaliurang Km. 14,5 Sleman Yogyakarta 55584, Indonesia \\ Email: galang.prihadi@uii.ac.id
}

\begin{abstract}
ABSTRAK
Kebutuhan akan darah pada proses transfusi darah terus meningkat tiap tahunnya. Peningkatan terhadap kebutuhan darah perlu diantisipasi melalui peningkatan kesadaran para masyarakat akan pentingnya aktivitas donor darah. Promosi terkait pentingnya donor darah terus dilakukan oleh PMI (Palang Merah Indonesia) selaku organisasi pemerintah yang berwenang mengelola aktivitas tersebut. Upaya-upaya tersebut umumnya dilakukan melalui pengembangan berbagai macam aktivitas yang melibatkan elemen masyarakat (baik orang tua, remaja, maupun anak-anak) agar dapat mengakses informasi terkait proses donor darah. Untuk mendukung aktivitas tersebut dibutuhkan suatu alat promosi yang dapat membantu masyarakat lebih mengenal proses donor darah. Penelitian ini dilakukan untuk mengembangkan sebuah alat promosi aktivitas donor darah dalam bentuk gim. Pengembangan gim diawali dengan menggali elemen gim potensial yang ada pada proses donor darah. Elemen gim tersebut kemudian digunakan sebagai dasar pada proses perancangan gim. Perancangan gim dilakukan dengan menggunakan metode perancangan storyboard. Hasil pengujian oleh pakar gim, relawan PMI, dan pengguna gim (kalangan anak-anak) melalui metode wawancara, didapatkan bahwa gim yang dibuat pada penelitian ini telah berhasil dibuat dengan baik.
\end{abstract}

Kata kunci: Donor; Gim; PMI; Promosi.

\begin{abstract}
The need for blood during the process of blood transfusion increases every year. This increasing need for blood must be anticipated through raising society's awareness of the importance of blood donor activities. Promotions regarding the importance of blood donation have been continuously done by the Indonesian Red Cross (PMI) as an authorized governmental organization. The efforts accomplished by the Indonesian Red Cross are typically done by developing various activities which involve the participation of ranging elements of the community (elderly, adolescent, and children) to access information regarding the process of the blood donor. To support these activities, a promotional tool is needed to help people get to know the blood donation process. This research is done to develop a promotional tool for blood donor activity in the form of a game. The game development starts by exploring the game components that can be used for the blood donation process. The model of the game component will then be used as a basis for the process of game planning. Game planning will be done using storyboard planning method. The results of the final test done by game experts, Indonesian Red Cross volunteers, and the game users (among children) through the interview method, it is concluded that the game as proposed in this research have successfully achieved its purpose.
\end{abstract}

Keywords: Donor; Game; PMI; Promotion.

\section{PENDAHULUAN}

Darah merupakan cairan dalam tubuh yang berfungsi mengirimkan zat dan oksigen yang dibutuhkan oleh manusia. Kekurangan akan darah di tubuh dapat membahayakan nyawa seseorang. Darah tidak dapat tergantikan dan tidak dapat dibuat oleh manusia (Fessehaye et al, 2011). Dalam kondisi kekurangan darah, seseorang hanya dapat menerima transfusi darah asli dari orang lain yang mendonorkan darahnya. 
Hal tersebut yang menyebabkan kebutuhan akan darah memiliki peranan penting dalam kehidupan manusia (Suwardie, 2013). Kebutuhan Permintaan akan kebutuhan darah dapat dipengaruhi oleh berbagai faktor, salah satunya adalah perubahan populasi umum (Greinacher et al, 2007).

Perubahan populasi umum dapat mempengaruhi angka permintaan darah. Dalam salah satu penelitian yang telah dilakukan, disimpulkan bahwa salah satu faktor yang menyebabkan peningkatan permintaan darah adalah penuaan populasi yang dipicu oleh besarnya kebutuhan darah bagi pasien lanjut usia (Borkent-Raven et al, 2010b). Penelitian tersebut menyimpulkan bahwa di Belanda, 59\% kebutuhan darah tersalurkan kepada para pasien berusia 65 tahun ke atas. Pada penelitian lainnya juga diramalkan bahwa kebutuhan darah akan meningkat menjadi $17,8 \%$ pada tahun 2015 setelah sebelumnya berada di angka $14,7 \%$ di tahun 2009 (Borkent-Raven et al, 2010a). Dengan proyeksi peningkatan kebutuhan pasokan darah tiap tahunnya, langkah yang harus dilakukan adalah mengupayakan pengurangan jumlah permintaan darah atau meningkatkan jumlah pasokan darah (Drackley et al, 2012).

Peningkatan permintaan akan kebutuhan darah perlu untuk diantisipasi dengan cara meningkatkan kesadaran para masyarakat akan pentingnya aktivitas donor darah (Domingos et al, 2016). Kesadaran akan pentingnya aktivitas donor darah juga telah mendorong banyak negara untuk mendirikan organisasi resmi yang bertugas melakukan pengelolaan aktivitas tersebut. Organisasi tersebut umumnya bernama Palang Merah atau dikenal juga dengan nama Red Cross. Di Indonesia sendiri, organisasi resmi yang diberikan mandat oleh Kementerian Kesehatan Republik Indonesia untuk mengelola aktivitas donor darah adalah Palang Merah Indonesia (PMI).

Dalam melakukan aktivitasnya, PMI memiliki tanggung jawab untuk menciptakan suatu sistem atau proses pengelolaan persediaan darah mulai dari proses pengumpulan, penyimpanan, hingga proses distribusi akhir. Proses pengelolaan persediaan darah tersebut memerlukan tingkat keamanan serta kepercayaan yang tinggi untuk tiap langkah prosesnya (Beliën and Forcé, 2012). Pada beberapa kasus, tingkat pemahaman proses pengelolaan darah sangat mempengaruhi motivasi para pendonor. Tingkat pemahaman yang rendah mendorong ketidakpercayaan masyarakat terhadap pengelolaan darah yang dilakukan. Hal tersebut dapat mengakibatkan tidak termotivasinya masyarakat untuk mendonorkan darahnya. Hal tersebut juga turut diperparah dengan keterbatasan lain terkait tidak banyaknya jumlah pasokan darah yang dapat didistribusikan dalam waktu yang relatif cepat sesuai dengan permintaan (Vanany et al, 2015).

Untuk dapat meningkatkan pemahaman masyarakat, PMI telah melakukan berbagai upaya dalam mengenalkan serta mempromosikan kegiatan donor darah di Indonesia. Upaya tersebut dilakukan melalui kegiatan-kegiatan pengenalan langsung yang melibatkan berbagai elemen masyarakat baik orang tua, remaja, dan anak-anak. Kegiatan pengenalan langsung dapat dilakukan dengan menggunakan alat atau metode khusus agar dapat menarik perhatian masyarakat. Salah satu caranya adalah dengan mengembangkan kanal informasi yang berisi konten-konten terkait dengan proses pengelolaan persedian darah di PMI. Untuk dapat menghasilkan dampak yang optimal, maka konten informasi tersebut juga perlu dibuat semenarik mungkin. Salah satu cara yang dapat dilakukan adalah dengan mengembangkan materi tersebut menjadi suatu konsep permainan (gim).

Konsep pengembangan suatu konten menjadi sebuah gim dapat membantu pemahaman teori, memicu gagasan, dan mendidik secara aktif namun tetap menyenangkan (Mustafee and Katsaliaki, 2010). Pemahaman yang baik melalui metode pembelajaran yang menyenangkan dapat meningkatkan motivasi para pemain untuk dapat terlibat lebih jauh dalam tema gim, khususnya pada kasus gim terkait pengelolaan persediaan darah (Domingos et al, 2016). Penelitian ini dilakukan untuk mengembangkan suatu permainan berbasis perangkat bergerak (mobile game) yang dapat digunakan sebagai alat promosi donor darah. Subyek dari penelitian ini adalah anak-anak (usia sekolah dasar) dari beberapa latar belakang yang berbeda. Gim dikembangkan dalam kaidah pembelajaran berbasis gim (game based learning) dengan pendekatan kondisi flow (flow state). Dengan rekayasa kondisi flow yang baik dan dipadu dengan game play yang menarik, gim yang dibuat pada penelitian ini diharapkan dapat digunakan sebagai alat pembelajaran sekaligus alat promosi proses donor darah. Dengan pengetahuan yang baik terkait proses donor darah, para pemain (anak-anak) diharapkan 
dapat tumbuh dengan kesadaran tinggi akan pentingnya aktivitas donor darah bagi dirinya dan orang lain.

\section{TINJAUAN PUSTAKA \\ 2.1 Pembelajaran Berbasis Gim (Game Based Learning)}

Gim memiliki kemampuan untuk memenuhi kebutuhan psikologis dasar para pemain untuk mengasah kemampuan, menentukan pilihan, dan menumbukan keterikatan dengan tema permainan (Ryan et al, 2006). Dengan kewenangan untuk melakukan determinasi (menentukan pilihan), para pemain dapat mendorong dirinya untuk terlibat dalam tema permainan dan menggunakan kemampuannya untuk melakukan aksi efektif dalam berinteraksi dengan lingkungan gim (Deci and Ryan, 2000). Secara sederhana, interaksi dalam gim menciptakan kecenderungan individu untuk mengeksplorasi sekaligus memanipulasi lingkungan dan secara aktif mencari tantangan untuk mengembangkan wawasan serta keterampilannya.

Gim merupakan salah satu mekanisme yang dapat digunakan untuk memotivasi peserta didik dalam suatu proses pembelajaran (Erhel and Jamet, 2013) melalui langkah persuasif (Peng et al, 2013). Pembelajaran dengan menggunakan gim dikenal dengan istilah gamebased learning (pembelajaran berbasis gim). Pembelajaran berbasis Gim telah terbukti efektif dalam meningkatkan motivasi para pemain untuk berpartisipasi dalam kegiatan pembelajaran (Hung et al, 2015). Pembelajaran berbasis gim memanfaatkan motivasi pemain dalam mengembangkan wawasan serta keterampilannya untuk kebutuhan pembelajaran suatu tema atau materi tertentu. Pada proses tersebut, konten materi dikembangkan menjadi suatu aset dalam gim berupa karakter, cerita, informasi, tantangan, misi, dan lain-lain.

\subsection{Kondisi Flow (Flow State)}

Kondisi flow adalah kondisi di mana seseorang terlibat dalam suatu pengalaman untuk melakukan kegiatan dengan kesenangan yang cukup besar (Hwang et al, 2012). Selama kondisi flow, seseorang akan terfokus pada suatu aktivitas yang didorong oleh tantangan atau tugas yang menarik untuk diselesaikan (Inal and Cagiltay, 2007). Dengan penyesuaian yang tepat, kondisi flow dapat menciptakan dampak positif melalui pengalaman bermain yang diarahkan untuk meningkatkan hasil belajar para pemain (Hung et al, 2015). Pada penelitian lain, kondisi flow dalam sebuah gim juga dapat mendorong peningkatan performa terkait penyelesaian masalah (problem solving) yang baik oleh para pemain terhadap suatu tema, konsep, atau tantangan (Chang et al, 2012).

Gim yang dikembangkan pada penelitian ini memanfaatkan kondisi flow yang memberikan pengalaman kepada para pemain dalam aktivitas pengelolaan persediaan darah di PMI. Keterikatan para pemain dalam memainkan gim tersebut diharapkan dapat memicu rasa penasaran mereka terkait proses donor darah dan mendorong mereka terlibat dalam kegiatan yang sesungguhnya.

\subsection{Elemen Gim (Game Elements)}

Elemen gim adalah seperangkat komponen yang digunakan untuk menyusun sebuah gim (Dos Santos et al, 2018). Dalam perkembangan penelitian di dunia gim, elemen gim juga disebut sebagai atribut gim (game attributes). Elemen gim memiliki berbagai unsur dengan istilah yang mungkin juga dapat berbeda. Contohnya adalah penggunaan istilah elemen "badge" di mana pada sebagian peneliti juga menggunakan istilah "emblem" (García et al, 2017). Elemen gim sangat mungkin untuk dikembangkan dalam berbagai aspek dan bersifat unik sesuai dengan kebutuhan dalam proses pengembangan gim itu sendiri (Dicheva et al, 2015).

Elemen gim mulai dikembangkan sejak era tahun 80-an dengan unsur awal berupa tantangan (challenge), rasa penasaran (curiosity), kontrol (control), dan fantasi (fantasy) (Dos Santos et al, 2018). Komponen tersebut kemudian diperluas dengan penambahan unsur-unsur pendukung seperti peran (role), konflik (conflict), aturan (rules), tujuan (goal), dan kendala (constrain).

Pengembangan lain dilakukan oleh Werbach dan Hunter (2012) yang menyusun elemen gim dalam 3 tingkatan, yaitu: komponen (components), mekanika (mechanics), dan dinamika (dynamics) dalam hubungan hierarki seperti pada Gambar 1. Bagian bawah dimulai dengan unsur components (komponen), sebagai unsur dasar dalam pengembangan gim. Unsur ini terdiri dari segala obyek yang menyusun sebuah gim. Unsur kedua di atas komponen adalah mechanics (mekanika). Unsur mekanika bertugas mengatur bagaimana seluruh komponen dapat bekerja dan berinteraksi dalam permainan sesuai dengan aturan yang ada. 
Contoh unsur mekanika antara lain: aturan, cerita, capaian, skor, bonus, waktu, tingkatan (level), pergerakan (movement), rintangan, dan lain-lain. Unsur tertinggi adalah dynamics (dinamika). Unsur dinamika merupakan unsur yang menarik pemain untuk terlibat dalam permainan. Unsur ini tercipta dari hubungan antar mekanik yang memicu para pemain untuk menyusun strategi dalam melakukan tindakan di dalam gim. Contoh unsur dinamika antara lain: Batasan pergerakan, emosi permainan, perkembangan kemampuan, hubungan antar pemain, umpan balik, dan lain-lain.

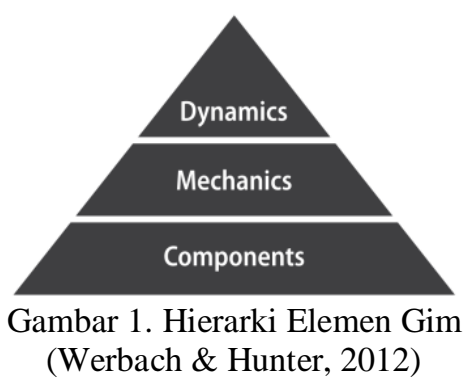

\section{METODOLOGI PENELITIAN}

Penelitian ini dilakukan dalam 4 tahap utama, yaitu tahap pengembangan elemen gim, tahap pemodelan, tahap pengembangan, dan tahap pengujian. Tahap pertama dilakukan dengan mempelajari proses-proses donor darah yang dilakukan di tempat pelayanan donor darah. Proses-proses tersebut kemudian di analisis dan dikembangkan menjadi elemen gim sesuai dengan kaidah yang dipaparkan oleh Werbach dan Hunter (2012). Tahap selanjutnya dilakukan dengan merubah elemen gim menjadi suatu rancangan aplikasi. Perancangan dilakukan dengan menggunakan metode perancangan storyboard. Tahap selanjutnya adalah tahap pengembangan yang dilakukan untuk merealisasikan perancangan menjadi suatu aplikasi berbasis perangkat bergerak. Tahap terakhir dari penelitian ini adalah pengujian. Tahap pengujian dilakukan untuk menguji sejauh mana aplikasi dapat bermanfaat untuk mendukung proses promosi donor darah. Pengujian dilakukan terhadap pakar gim, relawan PMI, dan pengguna gim (kalangan anak-anak) yang dilakukan melalui metode wawancara.

\section{HASIL DAN PEMBAHASAN \\ 4.1 Pengembangan Elemen Gim}

Dari hasil observasi dan wawancara terhadap beberapa relawan PMI, didapatkan bahwa prosedur donor darah diawali dengan pengisian formulir (pendaftaran), pengecekan darah, pemeriksaan dokter, pengambilan darah, lalu istirahat. Proses-proses tersebut saling mempengaruhi dan dilakukan secara sistematis (berurutan). Ketika tidak lolos dalam satu proses, maka pendonor tidak diperbolehkan untuk lanjut ke proses berikutnya. Kelima proses tersebut akan dimunculkan dalam gim sebagai elemen gim. Selain prosedur, faktor lain yang dapat menjadi elemen dalam gim adalah faktor pendonor. Pendonor dapat berhenti di suatu proses apabila dinyatakan tidak layak untuk melakukan donor. Gim yang dibuat harus dapat memberikan pilihan kepada pemain terkait apa yang harus dilakukan terhadap hasil dari suatu proses.

Tujuan utama dari proses donor darah adalah terpenuhinya target persediaan darah untuk masing-masing golongan. Terdapat 4 golongan darah yang harus terpenuhi, yaitu darah golongan $\mathrm{A}$, darah golongan $\mathrm{B}$, darah golongan $\mathrm{AB}$, dan darah golongan $\mathrm{O}$. Terpenuhinya kebutuhan atas 4 golongan darah tersebut juga akan digunakan sebagai elemen gim. Selain itu, variabel waktu juga akan digunakan untuk menambah tantangan dalam permainan. Waktu akan membatasi para pemain untuk dapat mengumpulkan darah sebanyak mungkin sesuai dengan batasan yang diberikan. Hal tersebut akan memaksa pemain menyusun strategi dan mengasah ketangkasan serta konsentrasinya untuk mendapatkan hasil terbaik.

Unsur komponen gim pada modul utama terdiri dari karakter (dokter, perawat, petugas, dan pendonor), kantor pelayanan donor darah, ruang tunggu, loket pendaftaran, ruang cek kesehatan, ruang periksa dokter, ruang donor, ruang istirahat, pintu keluar, pintu penjadwalan ulang, persediaan darah, skor, dan waktu. Unsur mekanika yang dibangun antara lain: kebutuhan akan masing-masing pasokan darah, pergerakan tiap pendonor menuju ke masing-masing proses, hasil masing-masing proses terhadap seorang pendonor, waktu tunggu untuk masing-masing proses, nilai kepuasan pendonor, waktu permainan, dan skor permainan.

Unsur dinamika yang dibangun adalah skor yang didapat dari kepuasan pendonor, waktu tercepat untuk menyelesaikan misi, waktu tercepat untuk menentukan keputusan dalam menempatkan para pendonor terhadap proses yang ada, dan pemenuhan kebutuhan darah yang tepat. Tiap proses donor darah memiliki waktu tunggu yang berbeda (ada yang cepat dan ada yang lambat), sehingga penentuan peletakan 
para pendonor dapat menjadi unsur dinamika dalam gim yang dikembangkan.

\subsection{Tahap Pemodelan}

Pemodelan gim dilakukan dengan menggunakan metode perancangan storyboard. Metode perancangan storyboard dipilih karena pengembangan gim dilakukan terhadap platform gim perangkat bergerak di mana tata letak (layout) memiliki porsi yang sangat penting. Pembuatan storyboard dilakukan berdasarkan elemen gim (unsur komponen, mekanika, dan dinamika) yang telah dikembangkan pada tahap sebelumnya. Untuk penyederhanaan penulisan, storyboard yang ditampilkan pada makalah ini hanya storyboard pada proses utama, yaitu proses permainan. Storyboard proses lain (proses menu, proses aturan main, proses tentang aplikasi) tidak ditampilkan karena tidak ada fungsionalitas serta visualisasi signifikan yang dibuat. Storyboard proses permainan dapat dilihat pada Gambar 2.

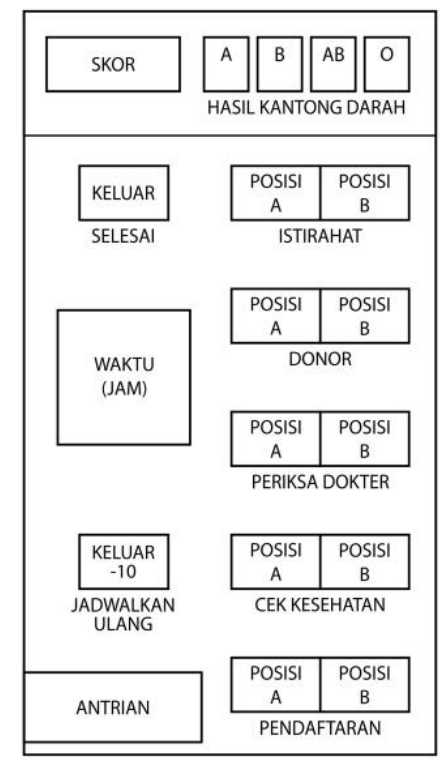

Gambar 2. Storyboard Proses Permainan

Proses permainan dimulai dari para pendonor yang datang pada area antrian. Pemain kemudian bertugas meletakkan para pendonor ke area selanjutnya sebelum waktu tunggu tiap pendonor habis. Ketika waktu tunggu tiap pendonor habis, maka pendonor akan menghilang dari permainan. Hal tersebut juga berlaku untuk tiap area. Menghilangnya pendonor tidak mengurangi skor permainan. Area selanjutnya untuk peletakan pendonor adalah area pendaftaran. Tidak ada pertimbangan khusus ketika memindahkan pendonor dari antrian menuju ke area pendaftaran.

Di area pendaftaran, para pendonor akan dilayani dalam waktu tertentu hingga dinyatakan selesai. Para pendonor akan memberikan informasi (berupa simbol) ketika proses pendaftaran telah selesai. Terdapat 2 posisi pada area pendaftaran. Tidak ada perbedaan dari kedua posisi tersebut. Setelah para pendonor selesai pada proses pendaftaran, pemain harus memindahkan pendonor ke area selanjutnya sebelum waktu tunggu pendonor habis. Pendonor akan menghilang dari permainan apabila waktu tunggunya habis. Menghilangnya pendonor akan mengurangi skor permainan sebesar 10 poin. Area selanjutnya untuk peletakan pendonor adalah area cek kesehatan.

$\mathrm{Di}$ area cek kesehatan, para pendonor akan diperiksa untuk pengecekan golongan darahnya. Para pendonor akan memberikan informasi (golongan darahnya) ketika proses cek kesehatan telah selesai. Sama seperti area pendaftaran, kedua posisi pada area kesehatan tidak memiliki perbedaan, keduanya memiliki waktu layanan yang sama. Pendonor juga akan menghilang dari permainan jika waktu tunggunya habis dan berdampak pada pengurangan skor. Setelah area kesehatan, para pemain dapat memindahkan pendonor ke dua tujuan, pertama adalah pintu keluar untuk penjadwalan ulang dan kedua adalah area periksa dokter untuk melanjutkan proses donor darah. Langkah pemindahan tersebut membangun unsur dinamika di mana para pemain harus membuat keputusan berdasarkan kondisi kebutuhan kantung darah yang ada dan waktu yang tersisa. Penjadwalan ulang akan berdampak pada pengurangan skor sebesar 10 poin.

Di area periksa dokter terdapat 2 posisi di mana keduanya memiliki perbedaan dari sisi waktu layanan. Posisi B memiliki kecepatan waktu layanan yang lebih cepat dari posisi A. Unsur dinamika dibentuk dari keputusan untuk menempatkan para pendonor (posisi A atau posisi B). Keputusan ditentukan dari strategi tiap pemain berdasarkan kondisi kantong darah yang dibutuhkan dan waktu permainan yang tersisa. Para pendonor akan memberikan informasi (berupa simbol) ketika proses periksa dokter telah selesai. Selain itu, pendonor akan menghilang dari permainan jika waktu tunggunya habis dan skor akan sekaligus berkurang. Area selanjutnya untuk peletakan pendonor adalah area donor. 
Area donor merupakan area di mana para pendonor melakukan proses donor darah. Sama seperti area periksa dokter, pada area ini terdapat 2 posisi di mana keduanya memiliki perbedaan waktu layanan. Strategi yang dilakukan juga tidak jauh berbeda dari area periksa dokter. Pendonor tidak akan menghilang pada proses ini, hanya saja lamanya waktu tunggu pendonor akan berdampak pada skor yang didapat. Semakin lama pendonor menunggu untuk dipindahkan ke area selanjutnya, maka semakin berkurang poin yang didapat. Poin maksimum adalah 50 (untuk kondisi pendonor tidak terlalu lama menunggu) dan minimum 20 (untuk pendonor yang sangat lama menunggu). Waktu tunggu pendonor merupakan unsur dinamika pada area ini, sehingga para pemain harus memberikan perhatian yang lebih pada area ini namun juga tidak mengacuhkan area yang lain. Setelah pendonor memberikan informasi telah selesai, para pemain dapat segera memindahkan para pendonor ke area istirahat.

Di area istirahat para pendonor akan memulihkan kondisi pasca proses donor yang telah dilalui. Para pendonor akan memberikan informasi (berupa simbol) apabila kondisinya telah pulih dan dapat meninggalkan layanan donor darah. Pendonor tidak akan menghilang dari permainan dan lamanya waktu tunggu pendonor tidak mempengaruhi skor yang didapat. Namun pada area ini hanya terdapat 2 posisi, sehingga para pemain perlu memindahkan pendonor ke pintu keluar agar pendonor berikutnya dapat mengisi posisi di area istirahat.

Lama permainan dibatasi oleh waktu yang diilustrasikan dalam bentuk jam dinding. Kantong darah terdiri dari 4 golongan darah di mana masing-masing golongan darah harus diisi oleh 10 orang pendonor (total 40 slot). Setiap slot yang terisi akan bernilai 30 (tiga puluh) poin. Selain pelayanan terhadap pendonor, kebutuhan untuk memenuhi kantong darah juga menjadi salah satu unsur dinamika pada gim. Skor permainan merupakan akumulasi dari poin pelayanan pendonor (maksimum 50 poin dan minimum 20 poin) dan poin kantong darah yang terpenuhi.

\subsection{Tahap Pengembangan}

Aplikasi yang telah dikembangkan dapat dilihat pada Gambar 3. Tata letak konten gim dikembangkan sesuai dengan storyboard yang telah dibuat pada tahap sebelumnya. Ilustrasi waktu permainan digambarkan sebagai jam waktu pelayanan yang dimulai dari pukul 08:00 hingga pukul 16:00. Selain itu ilustrasi kebutuhan darah juga dibuat dalam bentuk kantong darah yang terisi oleh darah. Tiap kantong akan terisi penuh apabila telah terisi oleh 10 pendonor. Tiap pendonor dipindahkan dengan teknik drag and drop (menggeser dan meletakkan).

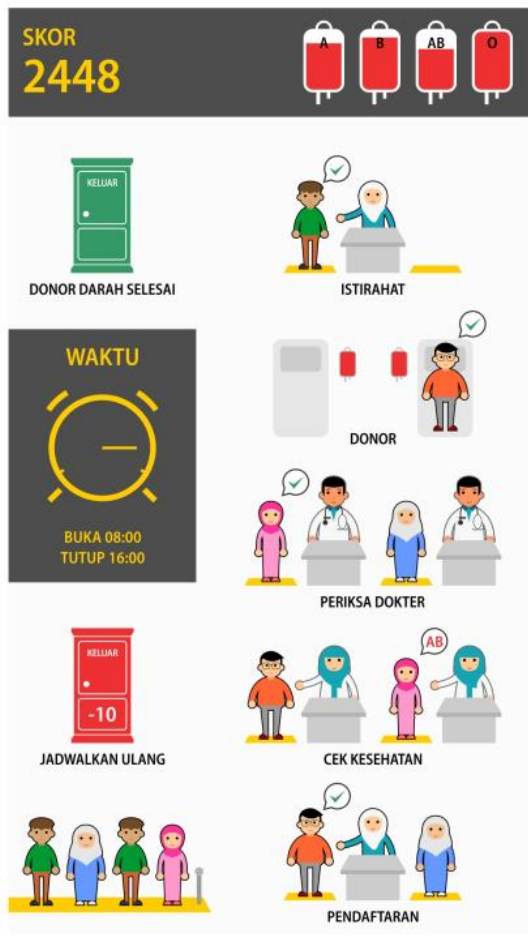

Gambar 3. Antarmuka Proses Permainan

\subsection{Tahap Pengujian}

Pengujian dilakukan terhadap 3 aktor utama yaitu pakar gim, relawan PMI, dan pengguna gim yang terdiri dari pengguna di kalangan anak-anak. Pengujian dilakukan melalui proses wawancara. Hasil pengujian terhadap pakar gim didapatkan kesimpulan bahwa gim yang dikembangkan telah memenuhi unsur tantangan untuk sebuah gim di mana para pemain diberikan kebebasan untuk menentukan strateginya dan memanfaatkan konsentrasinya untuk menyelesaikan misi gim. Berdasarkan sudut pandang visual, aplikasi yang dikembangkan telah sesuai dengan target pengguna, yaitu anak-anak. Pengembangan dapat dilakukan melalui teknik leveling (tingkatan permainan) sehingga para pemain dapat memainkan gim dalam waktu yang lama.

Pengujian selanjutnya dilakukan terhadap relawan PMI untuk menguji kesesuaian tiap proses pada gim yang dikembangkan. Tiap proses dalam gim telah sesuai dengan proses yang dilakukan pada pelayanan donor darah. 
Hanya saja terdapat penambahan proses yaitu penjadwalan ulang yang seharusnya tidak ada pada proses sesungguhnya. Untuk alasan pengayaan unsur dinamika dalam gim, proses tersebut diperbolehkan namun harus dilakukan dengan pendekatan khusus. Pengembangan ke depan dapat dilakukan dengan pembuatan modul proses distribusi darah yang juga merupakan bagian dari tugas PMI.

Pengujian terakhir dilakukan terhadap pengguna gim dari kalangan anak-anak. Bagi mereka, gim telah memiliki tampilan yang baik dengan cara penggunaan yang cukup mudah. Pengujian pemahaman konten yang diajarkan juga dilakukan dengan mengajukan pertanyaan seputar langkah-langkah pada proses donor darah. Sebagian besar pengguna gim dapat menjawab pertanyaan dengan baik, sehingga dapat disimpulkan bahwa aplikasi gim yang dibangun dapat menambah wawasan para pemain terkait proses donor darah. Namun beberapa menyampaikan bahwa gim yang bangun terlalu singkat untuk dimainkan.

\section{KESIMPULAN}

Gim pengenalan proses donor darah telah berhasil dibangun pada penelitian ini. Gim dibangun pada platform perangkat bergerak agar dapat memberikan kemudahan akses bagi para penggunanya. Fungsi gim sebagai media bantu dalam memberikan gambaran proses donor darah dapat dimanfaatkan sebagai alat promosi pada proses sosialisasi donor darah.

Kaidah pengembangan unsur komponen, mekanika, dan dinamika dari proses donor darah telah dikembangkan dengan baik sebagai elemen dalam gim yang dapat memberikan pemahaman para pemain terhadap proses tersebut. Manfaat gim terbukti dari hasil pengujian di mana para pemain dapat memahami proses donor darah dengan baik. Hasil tersebut juga dapat disimpulkan bahwa pembelajaran melalui pengalaman (experience) bermain gim dapat memudahkan penerimaan pemain terhadap suatu konten pembelajaran.

\section{DISKUSI}

Aplikasi gim yang telah dibangun masih perlu disempurnakan agar dapat menciptakan keterikatan para pemain terhadap gim yang dimainkan. Hasil pengujian masih didapati beberapa kekurangan dalam gim, khususnya terkait dengan durasi permainan yang terlalu singkat. Beberapa usulan yang terkumpul, pengembangan selanjutnya dapat dilakukan dengan 2 cara, yaitu penambahan dinamika gim melalui jalan tingkatan gim (leveling) atau dengan mengembangkan proses lanjutan dari proses donor darah, yaitu proses distribusi darah.

Tujuan utama dari gim ini adalah memberikan wawasan kepada para pemain terkait proses donor darah sehingga penelitian ini belum dapat menjawab pertanyaan terkait 'apakah gim yang dibuat dapat memotivasi para pemain untuk melakukan donor darah?'. Untuk menjawab pertanyaan tersebut perlu dilakukan penelitian lanjutan melalui pendekatan khusus seperti gamifikasi terhadap para pendonor.

\section{DAFTAR PUSTAKA}

Beliën, J. and Forcé, H. (2012), 'Supply Chain Management of Blood Products: A Literature Review', European Journal of Operational Research, 217(1), pp. 116.

Borkent-Raven, B.A., Janssen, M.P. and Van Der Poel, C.L. (2010a), 'Demographic Changes and Predicting Blood Supply and Demand in The Netherlands', Transfusion, 50(11), pp. 2455-2460.

Borkent-Raven, B.A., Janssen, M.P., Van Der Poel, C.L., Schaasberg, W.P., Bonsel, G.J. and Van Hout, B.A. (2010b), 'The PROTON Study: Profiles of Blood Product Transfusion Recipients in The Netherlands', Vox Sanguinis, 99(1), pp. 54-64.

Chang, K.E., Wu, L.J., Weng, S.E. and Sung, Y.T. (2012), 'Embedding Game-Based Problem-Solving Phase into ProblemPosing System for Mathematics Learning', Computers \& Education, 58(2), pp. 775-786.

Deci, E.L. and Ryan, R.M. (2000), 'The "What" and "Why" of Goal Pursuits: Human Needs and The Self-Determination of Behavior', Psychological Inquiry, 11(4), pp. 227-268.

Dicheva, D., Dichev, C., Agre, G. and Angelova, G. (2015), 'Gamification in Education: a Systematic Mapping Study', Educational Technology \& Society, 18(3), pp. 75-89.

Domingos, D.C., Lima, L.F., Messias, T.F., Feijó, J.V., Diniz, A.A. and Soares, H.B. (2016), 'Blood hero: An Application for Encouraging The Blood Donation by Applying Gamification', In Engineering in Medicine and Biology Society (EMBC), pp. 5624-5627. 
Dos Santos, A.L., Maurício, R.D.A., Figueiredo, E. and Dayrell, M. (2018), 'Game Elements for Learning Programming: A Mapping Study', CSEDU, 40, pp. 89101.

Drackley, A., Newbold, K.B., Paez, A. and Heddle, N. (2012), 'Forecasting Ontario's Blood Supply and Demand', Transfusion, 52(2), pp. 366-374.

Erhel, S. and Jamet, E. (2013), 'Digital GameBased Learning: Impact of Instructions and Feedback on Motivation and Learning Effectiveness', Computers \& Education, 67, pp. 156-167.

Fessehaye, N., Naik, D. and Fessehaye, T. (2011), 'Transfusion Transmitted Infections - A Retrospective Analysis from The National Blood Transfusion Service in Eritrea', Pan African Medical Journal, 9(1).

García, F., Pedreira, O., Piattini, M., CerdeiraPena, A. and Penabad, M. (2017), 'A framework for gamification in software engineering', Journal of Systems and Software, 132, pp. 21-40.

Greinacher, A., Fendrich, K., Alpen, U., and Hoffmann, W. (2007), 'Impact of Demographic Changes on the Blood Supply: Mecklenburg-West Pomerania as A Model Region for Europe', Transfusion, 47(3), pp. 395-401.

Hung, C.Y., Sun, J.C.Y. and Yu, P.T. (2015), 'The Benefits of A Challenge: Student Motivation and Flow Experience in Tablet-PC-Game-Based Learning', Interactive Learning Environments, 23(2), pp. 172-190.

Hwang, G.J., Sung, H.Y., Hung, C.M., Huang, I. and Tsai, C.C. (2012), 'Development of
A Personalized Educational Computer Game Based on Students' Learning Styles', Educational Technology Research and Development, 60(4), pp. 623-638.

Inal, Y. and Cagiltay, K. (2007), 'Flow Experiences of Children in An Interactive Social Game Environment', British Journal of Educational Technology, 38(3), pp. 455-464.

Mustafee, N. and Katsaliaki, K. (2010), 'The Blood Supply Game', In Proceedings of The Winter Simulation Conference, pp. 327-338.

Peng, W., Crouse, J.C. and Lin, J.H. (2013), 'Using Active Video Games for Physical Activity Promotion: a Systematic Review of The Current State of Research', Health Education \& Behavior, 40(2), pp. 171-192.

Ryan, R.M., Rigby, C.S. and Przybylski, A. (2006), 'The Motivational Pull of Video Games: A Self-Determination Theory Approach', Motivation and Emotion, 30(4), pp. 344-360.

Suwardie, A.W., Sopha, B.M. and Herliansyah, M.K. (2013), 'A Simulation Model of Blood Supply Chain at Indonesian Regional Red-Cross', Proceedings of The 2013 International Conference on Logistics and Maritime Systems.

Vanany, I., Maryani, A., Amaliah, B., Rinaldy, F. and Muhammad, F. (2015), 'Blood Traceability System for Indonesian Blood Supply Chain', Procedia Manufacturing, 4, pp. 535-542.

Werbach, K. and Hunter, D. (2012), 'For The Win: How Game Thinking Can Revolutionize Your Business', Wharton Digital Press, pp. 69-83. 